\title{
Longevity as an Animal Welfare Issue Applied to the Case of Foot Disorders in Dairy Cattle
}

\author{
M. R. N. Bruijnis • F. L. B. Meijboom • E. N. Stassen
}

Accepted: 17 January 2012/Published online: 2 February 2012

(C) The Author(s) 2012. This article is published with open access at Springerlink.com

\begin{abstract}
In current dairy farming it is possible to run a profitable farm without having to adapt the system to the needs of dairy cows. In such systems the interests of the farmer and animals often diverge. Consequently, specific animal welfare problems occur. Foot disorders in dairy cattle are an illustrative example resulting from the specific methods of housing and management in current dairy farming. Foot disorders and the resulting lameness are considered the most important welfare problem in dairy farming. However, these foot disorders not only typify welfare problems related to certain housing systems, but they also lead to the premature culling of cows. The assessment of the impact of foot disorders on the welfare of dairy cows raised the question of whether premature culling affects animal welfare since it affects the longevity of a cow. We argue that this aspect of longevity is morally relevant as an animal welfare issue. In this paper we aim to explore whether longevity is both (a) a morally relevant aspect in the discussion on killing animals and (b) a constitutive element of animal welfare. In other words, we aim to explore whether longevity is an independent moral argument in an animal welfare discussion. We claim that longevity is not merely important as an indicator of animal welfare, but is also a constitutive element of animal welfare. We argue that we need a more integrated approach to animal welfare and that an assessment that includes the aspect of time is necessary. This view involves a shift from views on animal
\end{abstract}

M. R. N. Bruijnis $(\bowtie) \cdot$ E. N. Stassen

Animal and Society, Department of Animal Sciences, Wageningen University,

P.O. Box 338, $6700 \mathrm{AH}$ Wageningen, The Netherlands

e-mail: marielle.bruijnis@wur.nl

F. L. B. Meijboom

Faculty of Humanities, Ethics Institute, Utrecht University, Janskerkhof 13a, 3512 BL Utrecht, The Netherlands

F. L. B. Meijboom

Faculty of Veterinary Medicine, Department of Animals in Science and Society,

Utrecht University, Yalelaan 2, 3584 CM Utrecht, The Netherlands 
welfare in terms of functioning or feeling well to a view on animal welfare that includes the aspect of natural living in which species-specific development is important. To show the impact of these points of view, we look at the practical implications for choices concerning the management of foot disorders in dairy cattle.

Keywords Animal welfare $\cdot$ Longevity $\cdot$ Dairy cow $\cdot$ Foot disorders

\section{Introduction}

Over the last few decades animal production, including dairy farming, has increased and specialized considerably, leading to intensification and scale enlargement. In the Netherlands, the average milk production in the past 10 years has increased from almost 7,500 1 per cow per year to approximately 8,000 1 nowadays $\left(\mathrm{LEI}^{1}\right)$. In the same period, the number of farms has decreased while the number of cows per farm has increased from an average of 60 to 75 dairy cows per farm $\left(\mathrm{LEI}^{2}\right)$. A labor and cost-effective housing system for such large herds of dairy cows is the cubicle housing system. Currently the main housing system in the Netherlands, it consists of cubicles where dairy cows can lie and rest and walking alleys, which mostly consist of concrete (slatted) floors. In these housing systems approximately $80 \%$ of the cows have one or more foot disorders, and about one-third of these cows become lame in a year (Frankena et al. 2009; Somers et al. 2003). Due to the incidence, duration and severity of these foot disorders and the resulting lameness, these problems are considered the main welfare issue for dairy cattle kept in cubicle housing systems (Algers et al. 2009; Anonymous 2001).

Foot disorders may cause long-lasting and intense pain. Consequently, the animal will experience difficulties in walking, lying down, and standing up (Cook and Nordlund 2009), affecting the ability of dairy cows to perform their natural behavior and fulfill species-specific needs. Furthermore, foot disorders affect other aspects of the cow's functioning, e.g., a reduced milk production (Warnick et al. 2001) and a diminished reproductive performance. As a result, cows suffering from clinical foot disorders have a higher probability of being culled (Machado et al. 2010). Even though the majority of foot disorders occur subclinically without causing lameness (Dyer et al. 2007), this "does not imply that an animal is not suffering" (Somers 2004).

In order to prevent or treat foot disorders, farmers, foot trimmers, and veterinarians are regularly confronted with the question of how this problem should be addressed. Should the foot disorder be treated or should the cow be culled or euthanized? Culling means the removal of a cow from the farm, in general for slaughter. A visibly lame cow, however, needs to be euthanized on the farm because of animal welfare and food security reasons and will therefore be destroyed instead of slaughtered for meat. In addition to the influence of specific economic

\footnotetext{
${ }^{1}$ LEI http://www3.lei.wur.nl accessed March 2011.

2 See footnote 1 .
} 
circumstances, the answer to these questions on how to treat foot disorders depends on one's view on animal welfare and touches upon the issue of longevity. Culling or euthanizing because of lameness implies the decision to end the life of an animal prematurely, i.e., before the end of a normally intended productive life, either because of direct welfare reasons or because the animal is not producing well and/or costs the farmer money and time (Booth et al. 2004).

In this paper the aspect of longevity implies the duration of life in terms of the intended lifespan of an animal. This topic has received considerable attention in the past few years. In the context of sustainable farming and improving farm management, dairy farmers aim to have robust and healthy cows that lactate easily and abundantly. Moreover, concern about the lifespan of dairy cattle has been put forward by the Farm Animal Welfare Council (FAWC 2009), who stated that a 2-year increase in lifespan would be desirable and possible. This would create a lifespan of 8 years, which equals a productive life of 6 years. Such an intended lifespan should be possible because a dairy cow can reach the age of 20 or more. In this paper we focus on the role of longevity before the cow reaches the intended life span because in Dutch society most people accept slaughtering animals for food (Rutgers et al. 2003).

While assessing the welfare impact of this most important welfare problem in dairy farming, the question emerged as to what extent premature culling has an impact on dairy cow welfare. It is agreed that a short lifespan can indicate an affected welfare (Broom 2007). In this paper we aim to go one step further and explore whether longevity is both (a) a morally relevant aspect in the discussion on killing animals and (b) a constitutive element of animal welfare. In other words, we aim to explore whether longevity is an independent moral argument in an animal welfare discussion.

We apply our analysis of longevity as a morally relevant welfare issue to the above-mentioned problems of foot disorders in dairy cattle. Our choice for this focus is not because foot disorders are the only problems in dairy cattle that lead to premature culling. Fertility problems would be important in this context too (e.g., Ahlman et al. 2011). However, foot disorders and lameness are highly important welfare problems in dairy farming that (a) are currently underestimated (e.g., Leach et al. 2010) and (b) lead to other health problems and dilemmas related to longevity.

\section{Modern Animal Farming and Related Animal Welfare Issues}

In general, it is currently possible to run a profitable farm that genuinely contributes to food security and food safety without having to adapt the housing system to the (behavioral) needs or interests of the individual animals. Consequently, the interests of farmer and animal diverge and give rise to animal welfare problems like behavioral and social restriction, overcrowding, and production-related diseases specific to the systems the animals are kept in (like foot disorders and lameness in dairy cattle). In situations in which the interests of farmer and animal diverge, problems of animal welfare do not merely result from cruelty or ignorance but they also start in the conflict between the interest in producing safe and cheap food in 
sufficient quantities and the interests of the animal (Rollin 2004). Nonetheless, the problems of animal welfare in general and, more specifically, the issue of foot disorders cannot be seen as a conflict of interests only (cf. Ohl and Van der Staay 2011). A clear moral dimension underlies the conflicts of interests themselves and the proposed answers to these conflicts. It is not only a matter of paying due respect to these interests, i.e., striving for what is most suitable for all involved parties, but it also touches upon fundamental moral questions of whether animals belong to our moral community and what we owe to animals. At this point, there is a plurality of views. The answers to the basic question of whether animals are part of our moral community are extremely diverse. Consequently, there are also many ideas on the content and relevance of animal welfare and on how to solve the current questions of animal welfare in animal production.

Thus the problem that started with a conflict of interests is rooted in a plurality of moral views on what we owe to animals. This plurality results in different views on animal welfare.

As the aim of this paper is to analyze whether longevity is a morally relevant issue within an animal welfare discussion, an analysis of longevity in relation to animal welfare is needed. In the next sections we discern six normative views that help to analyze longevity as a moral issue. First, we shortly discuss two views that link the moral importance of longevity to the value of life rather than to animal welfare. Second, we make a more detailed analysis of four views on longevity in relation to animal welfare. Finally, we draw conclusions on the relevance and implications of longevity as an animal welfare issue.

\section{Longevity, the Value of Life and Respect for Individuality}

A first view that considers longevity as a morally relevant aspect starts with the idea of respect for life. Respect for life, according to Taylor (1986), means that life as such is worthwhile protecting if a being has a "good of its own." From this perspective interfering in the lifespan of a living being that has a good of its own is morally problematic as it affects the good of the animal and runs counter to the duty to pay due respect to each being that has a good of its own. However, to come to this conclusion, this view on respect for life does not need to refer to animal welfare. Thus in this view longevity is a morally relevant aspect but not as an issue of animal welfare.

A second view starts with "respect for individuality" in which those who are subject-of-a-life have inherent worth ${ }^{3}$ and as such are worthwhile protecting (Regan 1983). Therefore, interfering in the life span of a subject-of-a-life is a no-go area. Animal capacities like having a future orientation, awareness, or self-awareness are relevant if these capacities are a condition for a being to be defined as subject-of-alife and therefore give much importance to longevity. However, just as with a

\footnotetext{
3 Regan speaks about inherent value, but this has a stronger claim than the classical use of the concept as introduced by Lewis (1946). Therefore, we speak of inherent worth.
} 
Taylorian account, the line followed by Regan will grant longevity moral importance but not as an issue of animal welfare.

According to these views of "respect for life" and "respect for individuality" the question of longevity raised in the welfare assessment of the treatment of foot disorders is appropriate because it is a morally relevant aspect in the discussion on killing animals; nevertheless, it is not genuinely linked to animal welfare. Moreover, the relevance of longevity is not considered to be specific to housing or management-related animal diseases (like foot disorders). The "respect for life" and "respect for individuality" views consider keeping animals for production aims highly problematic, if not fully unacceptable. An evaluation of this latter normative claim is beyond the scope of this paper. However, these views do not directly explain why longevity is also mentioned in animal welfare discussions by people who appear to have no fundamental problems with keeping animals for food production. Therefore, we now wish to look at normative views in which animal welfare plays a central role.

\section{Longevity and Animal Welfare}

In the practice of animal production, welfare issues arise since animal interests are at stake. As Yeates (2009) states; “... one condition for an issue being a welfare issue is that its assessment as an issue involves (or ought to involve) an evaluation of states with regard to an animal's interests." In line with what we have claimed about interests in the introductory section on the conflicts in the practice of animal production, speaking about the interests of animals is also not a value-free act. Starting animal welfare discussions from the viewpoint of animal interests perfectly shows the interrelation of the normatively and biologically based elements of animal welfare.

Both biological and normative assumptions define to what extent an animal has interests, what these interests are and what they imply for our dealings with animals. The combination of one's biological and normative value assumptions leads to specific views on animal welfare and-as we claim-also on whether longevity is an aspect that has added value in the welfare discussion. This can be illustrated by combining three views on animal welfare based on biological knowledge (e.g., biology, ethology, and physiology) with four views based on moral norms on animals and their welfare. For the biologically based views on animal welfare, we-following Fraser-distinguish three views: animal welfare as a matter of functioning well, feeling well, and leading natural lives (Fraser et al. 1997). We are aware that, in practice, these often overlap. However, in essence they have different biological starting points in which the different views do not rule out the previous view(s), e.g., when the view on feeling is adopted, the functioning view continues.

Moreover, these biological views can be related to the four normative views about animal welfare that we distinguish and that indicate the moral importance of animal welfare and our duties towards animals. The normative views assume that sentient beings should (a) be able to function well, (b) feel well, (c) be able to satisfy 
Table 1 Relation between biological and normative views on animal welfare and the relation with longevity. Starting as an indicator and evolving into an independent moral argument

\begin{tabular}{lll}
\hline $\begin{array}{l}\text { Biological views on } \\
\text { animal welfare }\end{array}$ & $\begin{array}{l}\text { Normative views on animal } \\
\text { welfare evaluation }\end{array}$ \\
\hline Functioning, health $\longrightarrow$ Functioning well & Role that longevity plays \\
Feeling & Feeling well \\
Natural living & Preference satisfaction \\
& Species-specific \\
& Development
\end{tabular}

preferences, and (d) should be able to develop according to species-specific needs and capabilities.

If the three biological views on welfare are combined with the four normative views, we do not end up with a matrix of twelve possible views on animal welfare because consistency requires a certain balance in biological and normative views. It would, for instance, be problematic to stress the importance of species-specific behavior in biological terms but deny the moral importance of satisfying speciesspecific needs at the same time. Table 1 shows the relevant views and the role longevity plays in these views on animal welfare. In the next sections we elaborate on three roles longevity can play in the animal welfare debate. Starting as an indicator and evolving into an independent moral argument, the latter making it an animal welfare issue.

\section{Longevity as Indicator of Animal Welfare}

A first view on animal welfare focuses on the functioning and health of the animal; here welfare implies that the animal is free from diseases and has the ability to function well, e.g., the ability to grow and to reproduce. Farmers in particular use this view on welfare when, for instance, they argue that if they take good care of the animals, the animals will produce well and therefore enjoy good welfare (De Greef et al. 2006). From this perspective a reference to longevity is not part of the concept of welfare but is an indicator of welfare. Longevity indicates that the animal's health and functioning is not compromised to such an extent that the life span is affected.

This idea of longevity as an indicator of welfare can also be recognized in those views that include the feelings of animals in the concept of welfare (Broom 1986, 2007; Bracke and Hopster 2006). By stressing the role feelings play in relation to welfare, some go further by arguing that, in addition to avoiding negative welfare, positive feelings are essential for animal welfare (Spruijt et al. 2001). This view often comes with the moral claim that animals—as sentient beings who can feel pain - should be granted moral status and are legitimate objects of moral concern.

Nonetheless, the emphasis on feelings does not necessarily imply that longevity plays a role as an independent moral argument in welfare discussions. It is often considered that death and longevity as such are not an animal welfare issue (e.g., 
Broom 1988; Webster 1995). From this perspective, the moral intuition that killing includes a moral wrong is not denied, but it is argued that longevity is not a legitimate argument to substantiate this intuition. Those upholding this view argue that longevity is not relevant because animals have no or an insufficient concept of time. Consequently, they lack the awareness of their future and cannot weigh future benefits against current misery. Thus an animal does not comprehend extra life (cf. Lund and Olsson 2006; Rollin 2006). The argument usually includes the following steps: a cow on a dairy farm has to be culled anyway. If the animal is culled in a welfare-neutral way, then there is no harm in killing animals because for the cow it does not matter whether and at what age it will be culled. Thus longevity only plays a role as an indicator of (restricted) animal welfare. For instance, if an animal is culled prematurely because of health and welfare problems, restricted longevity is often seen as an indicator of reduced animal welfare (e.g., Broom 2007).

In the case of foot disorders, longevity indicates animal welfare problems if many cows are culled due to such disorders. Culling healthy cows before the intended lifespan has been reached is not a welfare issue as such. For instance, when the farmer wants to replace dairy cows with genetically superior young stock, there are no welfare problems because killing is not seen as a welfare issue. If a cow has a foot disorder that is treatable and can result in recovery, a dairy farmer has to decide whether to treat or prematurely cull the cow. In general this assessment depends on how likely recovery will be, the probability that the foot disorder will return and to what extent the cow is affected in its functioning and feeling. Specific decisions need to be made for the different foot disorders of varying severity. As long as the killing itself is not seen as problematic for animal welfare and reduced longevity can only indicate affected welfare, then the decision depends on how the farm-technical aspects are weighed against the functioning and feeling of the cow. A decision to bring the cow to slaughter can be seen as a good solution because it will stop the negative impact on welfare.

This may result in a counterintuitive situation. Because killing the animal is not a welfare issue and it even might be the preferred option if the cows really suffer or if they do not function properly from the perspective of production, then a herd-level welfare assessment might give the impression that such a farm scores well on animal welfare. Relatively few animals have a health problem at the moment of assessment. However, in reality this so-called positive result is achieved because the problems affecting welfare are "solved" by culling or euthanizing the animals rather than by improving animal welfare by better prevention and earlier treatment of foot disorders.

\section{Longevity as a Precondition for Animal Welfare}

The view on welfare that considers the feelings of animals as the key element of animal welfare also includes the possibility of considering longevity as a precondition for animal welfare rather than an indicator only. Sapontzis already argued that life has important instrumental value, for living things that have interests (1987, 166-170). Without continuing to live, the animal cannot fulfill its interests. 
From this perspective, a premature death not only implies depriving an animal of its life, but it also "deprives it of a future in which it could pursue its interests" (Haynes 2008, p, 54). Balcombe (2009) starts from a hedonistic utilitarianism and argues: "Pleasure has moral import for practises like factory farming and laboratory research, for it amplifies the moral burden of depriving animals the opportunity to lead fulfilling enjoying lives." From a similar normative perspective, Bradley (2009) states: "There is no good reason to discount the badness of death for an animal. If an animal would have had a good life, then killing it is bad for it, even if it cannot contemplate its future."

From this view, being alive is a precondition. It is a condition sine qua non to be able to feel and to experience positive feelings as something intrinsically good. Depriving an animal of a positive future harms it because positive welfare is taken away (Balcombe 2009). Consequently, this view considers lifespan as a relevant notion in the moral assessment of a practice of animal use because the duration of life directly influences the ability to have positive experiences. ${ }^{4}$

It is now possible to explore the implications of the views on welfare that are based on the animals' feelings in the case of foot disorders. In comparison to health and functioning, feelings play an especially important role in deciding whether the cow has a life worth living (feeling well). Compared to the functioning views, the affected welfare during the presence of a foot disorder needs to be considered in addition to the production level and health parameters. The use of analgesics for lame cows is not a common practice in dairy farming ( $O^{\prime}$ Callaghan 2002). Improving welfare by better pain medication and increased cow comfort, like improving lying and walking surfaces for at least the lame cows, should be given more attention and put into practice according to the views on feeling. The extent to which the dairy farmer will implement these measures to promote animal welfare depends on the practical and economic possibilities as well as the farmer's assessment of the negative welfare impact of the various foot disorders. The decision to cull a cow could also be for the sake of the cow because cows might suffer too long. This shows that longevity is more than a mere indicator of welfare but it is still not morally relevant for its own sake. Longevity is a welfare issue that needs to contribute to the quality of the life of the animal.

Because the aim of this paper is to explore whether longevity is both (a) a morally relevant concept in the discussion on killing animals and (b) a constitutive element of animal welfare, the idea of longevity as a precondition does not appear to meet both conditions. From Sapontzis's viewpoint and from the viewpoint of hedonistic utilitarianism, lifespan is not morally irrelevant but it does not serve as a constitutive element in the moral assessment of animal use or animal welfare. Since only fulfillment of interests or pleasure are considered to be intrinsically good, longevity does not play an independent role.

\footnotetext{
4 A cynical counterargument in relation to (dairy) farming could be that it is questionable in the first place whether dairy cows have a good life at all. In this paper we assume that keeping dairy cows does not exclude the premise that cows can have a life worth living.
} 
Longevity as an Independent Moral Argument in the Animal Welfare Discussion

\section{Preference Satisfaction}

Animal welfare defined in terms of animal feelings can be combined with the normative view on preference satisfaction. In short, this implies that the moral good entails maximizing preference satisfaction, and that animal welfare holds that satisfying animal preferences will result in positive feelings. An animal can have a whole range of preferences to satisfy, including the preference to survive. If this latter preference is at stake, then (a) longevity should be included in the ethical assessment of animal welfare (cf. Singer 1993) and (b) longevity can then be seen as a welfare issue since killing the subject results in the frustration of its preference and negatively affects the overall welfare.

Nonetheless, one can argue that the added value of longevity for the ethical discussion on welfare, and especially on premature killing, is still marginal for two reasons. First, the desire to stay alive is only but one possible preference that needs to be balanced against other preferences of the animal and those of other sentient beings involved. A reference to longevity as such is not a sufficient argument to understand or justify the moral intuition that premature killing is a moral wrong. This is related to the problem of comparing welfare states. However, at this point lifespan can make a genuine contribution. To judge what is better or worse in terms of (overall) welfare depends on what will happen in the future. An example is tail docking in pigs. Tail docking in pigs is performed regularly on pig farms even though many farmers do not have any experience with the problem of tail biting on their farm (De Lauwere et al. 2009). Although the occurrence of tail biting in the future is not a certainty, to prevent the detrimental effects of this behavior the tail is docked. The docking itself is painful, but it is not certain whether the procedure is needed to prevent the even more severe effects of tail biting. Citing examples like this one Yeates (2009) states: "It follows from this comparative nature of (at least much of) welfare assessment that the value of a welfare state may depend not only on what that state included in itself, but also on what states would otherwise be present." The assumption that animal welfare is more than only the feeling and interests of the animal in the present makes it possible to state that future welfare and future interests will be infringed when the animal is killed. Thus comparing different states of welfare includes more than the present state of the animal; it is also about what has been and what will be (Yeates 2009). From this perspective longevity is more than merely an indicator or precondition of animal welfare. It is a way to grasp the future preferences of an animal in the process of comparing preferences.

The second reason that longevity is marginal to the ethical discussion on animal welfare is that the preference to stay alive and live a long(er) life relates to consciousness and to the capacity to have a minimum idea of concepts such as life, death, and the future. This confronts us with some serious empirical questions, i.e., is it possible to scientifically determine whether animals do have a future orientation and, if so, whether they prefer to stay alive? The answers to these questions are still uncertain. DeGrazia (1996), for example, argues that sentient animals have desires 
and that some of them have a sense of time in terms of a memory (sense of the past) or a sense of the future (anticipation). He emphasizes that the level of having desires and a sense of time can be different from that of humans but that the level is not decisive for acknowledging its moral importance. It is about whether there is some perception of time or not. If so, then the animal is not stuck in the present and will have interests in more than present experiences only. Based on empirical findings, there are indications that animals do have the capacity to have a future orientation. For instance, Kotler et al. (1999) showed that squirrels can balance present and future needs when foraging for food for the winter. Of course, this does not result in conclusive arguments on the capacities of other animals such as the cow with a foot disorder. However, there are two reasons why we may argue that such a cow can have preferences about her future. On the one hand, it is likely that a cow, a mammal as well, has similar cognitive capacities and therefore has a future orientation. On the other hand, even without conclusive evidence we have a strong moral reason to treat animals, such as cows, as having the capacity to have preferences about their future. This is justified based on a precautionary reasoning. The fact that there is a possibility that animals have some future orientation is enough to give the animals the benefit of the doubt. This illustrates that-even if we take the empirical uncertainty seriously with respect to animals' consciousnesslongevity can serve as an independent moral argument in the animal welfare debate.

The application of this view implies that if an animal has a sense of the future and if there is future welfare at stake, then this plays an important role in deciding whether to treat or to cull a cow. It is no longer possible to decide based on the present situation only. Culling a healthy cow then implies the risk of an affected welfare because the animal's potential preference for life will be affected and the possibility of satisfying future preferences may be frustrated. This also holds for a foot disorder that is likely to result in full recovery without a long and painful disease process. According to the view of preference satisfaction, the interests of the animal in terms of missed future welfare and the preference for life need to be weighed against the interests of the farmer. Compared to the above-discussed views on longevity, the premature culling of dairy cows needs justification because of the welfare impact of living a shorter life. Another consequence is that efforts to prevent and treat foot disorders have relatively more weight compared to the situation where longevity is only an indicator or precondition.

\section{The Importance of Species-Specific Development}

In the public debate animal welfare is not only framed in terms of functioning and feeling but it also includes the aspect of natural living. This entails the ability to perform natural behaviors and fulfill (behavioral) needs that are important to and characteristic of that species. At this point there has been a clear change in the perception and evaluation of animals. Cohen et al. (2007) state: "The relationship between man and animal has in recent years evolved from a purely functional relationship in which the animal is valued mostly for its instrumental utility to humans towards one in which respect for the value of the animal as a being in its own right plays a significant role." For instance, the cow's need to walk outside or 
the chicken's need to have the opportunity to take a dust bath are considered to be essential elements for a good animal life and therefore necessary to justify animal use.

The focus on natural living is not restricted to the public debate. It can also be recognized in the research on animal welfare. The attention to natural living often starts in a view on welfare that integrally assesses the life of an animal. This implies that a focus on "mental state" and subjective experiences are combined with objective characteristics of the quality of life (e.g., whether the animal is able to perform its species-specific behavior) and satisfaction of preferences during life. From this perspective, natural living implies that the animal has to be able to live according to its nature. In other words, the animal has to be able to perform speciesspecific behavior. To explain the notion of species- specific behavior, Fraser (1999) refers to the Aristotelian concept of telos that has been elaborated by Rollin (2004): "... animals have natures of their own (telos), and interests that flow from these natures...."

The emphasis on natural living has implications for the relevance and applicability of the notion of longevity as a welfare issue. The question is no longer whether animals suffer from an early death, but to what extent does an early death frustrate the aspect of natural living and the ability to perform species-specific behavior. An example of such a view is Nussbaum's capabilities approach. She argues that humans and animals have certain species-specific goals and that these beings should be able to develop these specific abilities and skills in order to flourish and to live according to their telos. In this view longevity clearly becomes a welfare issue because the possibility of developing species-specific abilities refers not only to functioning and feeling in the present-as it is traditionally perceived in the functioning and feeling views-but it also refers to a certain lifespan. Welfare in terms of flourishing and living a life that is in line with the telos of that subject implies a welfare approach that assesses welfare over time and takes an integral perspective. The aspect of time emphasizes that welfare should be measured and assessed during a longer period rather than at single time points only. For example, an elephant's long-lasting search for food or water in dry areas in order to survive involves discomfort but fits in the adaptive and natural capacities of the animal. Consequently, the elephant's overall welfare over time might not be compromised because this search is needed to survive and it enables the animal to have positive welfare in the future and to develop characteristics needed to survive as an individual and as a species. Consequently, lifespan is a relevant welfare criterion. The integral perspective, in which more than only the functioning and feelings of the animals in the present is of importance, implies that the relevance of longevity is not restricted to the animals' capacity of being aware of their own future because flourishing is worthwhile striving for in itself. Because this implies a certain lifespan, longevity is a constitutive element of animal welfare.

For dairy farming this implies that longevity gets more weight in culling decisions about healthy cows and cows with a health problem. Farmers and their advisors are confronted with cases of foot disorders needing a diagnosis about treatability. Since this diagnosis is not value free, farmers can value the same situation differently. For example, one farmer might judge a lame cow with a sole 
ulcer not to be a real welfare problem for the animal and he would thus be less inclined to treat the cow quickly after having discovered it is lame. However, another farmer might recognize this as a welfare issue and take action. Sometimes there are clear cases in which all agree that the animal's welfare is affected very severely by the disorder and that the life of the animal cannot be improved by treatment. Then killing can be in the animal's interest whether you consider it from the perspective of biological functioning, feeling, or natural living. Based on the prima facie responsibility to kill an animal that would otherwise have a life worth avoiding (Yeates 2009), it is necessary to know when there is no treatment or improvement possible in order to prevent the animal from suffering needlessly before being killed.

In other cases, the situation is more complicated because of the uncertainty about the need or the possibility of treating the animal. In those cases the broader view on welfare requires taking the aspect of longevity into account as an independent argument. The lifespan of the animals has to be weighted against different interests in animal food production. The interests of the animals get more weight if one starts from the assumption that an animal's ability for species-specific development should be taken seriously.

This could result in an increased age of dairy cattle because welfare that includes longevity is given more weight. This requires management and housing that improves prevention strategies and the treatment of health issues. ${ }^{5}$ On top of this, this view meets the moral intuition that killing animals raises moral questions. From this perspective, there is a clear need to justify the culling of animals because the lifespan of the animals receives more value than in the more restricted views on welfare (functioning and feeling). Whereas in those restricted views culling healthy or treatable animals is not seen as a welfare issue for the individual animal, in the broader view culling affects the welfare of animals. This means that prematurely culling dairy cows for farm-technical reasons becomes an animal welfare issue even if the animal has no direct physical or mental discomfort. Based on this view we can make a step from longevity as an indicator or as a precondition for animal welfare to the idea of longevity as a constitutive element of animal welfare. This, however, requires including the integral lifespan and the development and capacities of the individual animals in the welfare assessment.

\section{Conclusion}

We conclude that longevity should be considered as a constitutive element of animal welfare rather than as a mere indicator of animal welfare. We have shown that this view involves two steps.

The first step is moving from welfare as a concept based mainly on biological knowledge to the notion that animal welfare is based on and informed by biological

\footnotetext{
5 We are aware that if dairy cows are able to have a longer productive life, the bases and management of dairy farming need to be reconsidered to prevent potential other or new dilemmas. However, such dilemmas should not prevent us from discussing the role of longevity in the welfare of dairy cows.
} 
knowledge but is equally driven by moral norms. Consequently, what we owe to animals can be interpreted more broadly than merely preventing physical or mental discomfort (views on functioning and feeling). It also includes the duties to enable animals to flourish and live a natural life, which comes with an emphasis on longevity.

A second step is moving from views on animal welfare in terms of functioning or feeling well to a view on animal welfare that includes the aspect of natural living in which species-specific preferences and species-specific development are important. We argue - by using both normative and biologically based arguments- that animal welfare should be approached more integrally and that it should be assessed over time. Therefore, the animals' adaptive and natural capacities should be a key element in defining welfare rather than a single focus on the animals' functioning or feelings at a certain moment.

This point of view allows us to evaluate the welfare of animals from the perspective of the whole lifespan of an animal. This interpretation is independent of the capacity to comprehend life or have a future orientation. It is important that animals are able to live a life in which they can adapt to fulfill their preferences and show species-specific behavior.

In the public debate on animal husbandry, this view enables us to understand and address the moral intuition that killing animals includes a moral wrong even if the act of killing is performed in a welfare-neutral way. Longevity as a welfare issue shows that killing should not only be evaluated from the perspective of the direct act but should also take the future abilities to flourish into account.

In the practice of dairy farming, considering longevity as a welfare issue can be a useful tool in assessing welfare and managing foot disorders in dairy cattle. It implies that premature culling, i.e., cull the animal before the end of a normally intended productive life, is not a neutral act but one that can affect animal welfare because of its implications for the longevity of a cow. This broadens the scope of evaluating foot disorders. Rather than merely focusing on whether a foot disorder is evaluated in terms of the cow's ability to function in a certain system, this view requires an assessment in which all the interests of an animal, including those related to lifespan, are taken seriously.

Acknowledgments We would like to thank the anonymous reviewers for their helpful comments on an earlier version of this paper.

Open Access This article is distributed under the terms of the Creative Commons Attribution License which permits any use, distribution, and reproduction in any medium, provided the original author(s) and source are credited.

\section{References}

Ahlman, T., Berglund, B., Rydhmer, L., \& Strandberg, E. (2011). Culling reasons in organic and conventional dairy herds and genotype by environment interaction for longevity. Journal of Dairy Science, 94, 1568-1575.

Algers, B., Bertoni, G., Broom, D. M. , Hartung, J., Lidfors, L., Metz, J.H. M., Munksgaard, L., Nunes Pina, T., Oltenacu, T., Rehage, J., Rushen, J., Smulders, F., Stassen, E. N., Stilwell, G., Waiblinger, 
S., \& Webster, A. J. F. (2009). Scientific report on the effects of farming systems on dairy cow welfare and disease, prepared by Animal Health and Animal Welfare Unit of the European Food Safety Authority (EFSA).

Anonymous. (2001). "Scientists" assessment of the impact on housing and management on animal welfare. Journal of Applied Animal Welfare Science, 4, 3-52.

Balcombe, J. (2009). Animal pleasure and its moral significance. Applied Animal Behaviour Science, 118, 208-216.

Booth, C. J., Warnick, L. D., Grohn, Y. T., Maizon, D. O., Guard, C. L., \& Janssen, D. (2004). Effect of lameness on culling in dairy cows. Journal of Dairy Science, 87, 4115-4122.

Bracke, M. B. M., \& Hopster, H. (2006). Assessing the importance of natural behavior for animal welfare. Journal of Agricultural and Environmental Ethics, 19, 77-89.

Bradley, B. (2009). Well-being and death. New York: Oxford University Press Inc.

Broom, D. M. (1986). Indicators of poor welfare. British Veterinary Journal, 142, 524-526.

Broom, D. M. (1988). The scientific assessment of animal welfare. Applied Animal Behaviour Science, $20,5-19$.

Broom, D. M. (2007). Quality of life means welfare: How is it related to other concepts and assessed? Animal Welfare, 16, 45-53.

Cohen, N. E., Van Asseldonk, M. A. P. M., \& Stassen, E. N. (2007). Social-ethical issues concerning the control strategy of animal diseases in the European Union: A survey. Agriculture and Human Values, 24, 499-510.

Cook, N. B., \& Nordlund, K. V. (2009). The influence of the environment on dairy cow behavior, claw health and herd lameness dynamics. The Veterinary Journal, 179, 360-369.

De Greef, K., Stafleu, F., \& De Lauwere, C. (2006). A simple value-distinction approach aids transparency in farm animal welfare debate. Journal of Agricultural and Environmental Ethics, 19, 57-66.

De Lauwere, C., Hoogendam, K., Zonderland, J. J., \& Bracke, M. B. M. (2009). Stoppen met couperen? Varkenshouders over staartbijten en staartcouperen, LEI.

DeGrazia, D. (1996). Taking animals seriously: Mental life and moral status. Cambridge: Press Syndicate of the University of Cambridge.

Dyer, R. M., Neerchal, N. K., Tasch, U., Wu, Y., Dyer, P., \& Rajkondawar, P. G. (2007). Objective determination of claw pain and its relationship to limb locomotion score in dairy cattle. Journal of Dairy Science, 90, 4592-4602.

FAWC, Farm Animal Welfare Council. (2009). Opinion on the welfare of the dairy cow, London.

Frankena, K., Somers, J. G. C. J., Schouten, W. G. P., Van Stek, J. V., Metz, J. H. M., Stassen, E. N., et al. (2009). The effect of digital lesions and floor type on locomotion score in Dutch dairy cows. Preventive Veterinary Medicine, 88, 150-157.

Fraser, D. (1999). Animal ethics and animal welfare science: Bridging the two cultures. Applied Animal Behaviour Science, 65, 171-189.

Fraser, D., Weary, D. M., Pajor, E. A., \& Milligan, B. N. (1997). A scientific conception of animal welfare that reflects ethical concerns. Animal Welfare, 6, 187-205.

Haynes, R. (2008). Animal welfare: Competing conceptions and their ethical implications. Dordrecht: Springer.

Kotler, B. P., Brown, J. S., \& Hickey, M. (1999). Food storability and the foraging behavior of fox squirrels (Sciurus niger). The American Midland Naturalist, 142, 77-86.

Leach, K. A., Whay, H. R., Maggs, C. M., Barker, Z. E., Paul, E. S., Bell, A. K., et al. (2010). Working towards a reduction in cattle lameness: 1. Understanding barriers to lameness control on dairy farms. Research in Veterinary Science, 89, 311-317.

Lewis, C. I. (1946). An analysis of knowledge and valuation, The Paul Carus Lectures, Series 8, 1946, Open Court, La Salle.

Lund, V., \& Olsson, I. (2006). Animal agriculture: Symbiosis, culture, or ethical conflict? Journal of Agricultural and Environmental Ethics, 19, 47-56.

Machado, V. S., Caixeta, L. S., McArt, J. A. A., \& Bicalho, R. C. (2010). The effect of claw horn disruption lesions and body condition score at dry-off on survivability, reproductive performance, and milk production in the subsequent lactation. Journal of Dairy Science, 93, 4071-4078.

O' Callaghan, K. A. (2002). Lameness and associated pain in cattle-Challenging traditional perceptions. In Practice, 24, 212-219.

Ohl, F., \& Van der Staay, F. J. (2011). Animal welfare: At the interface between science and society. The Veterinary Journal. doi:10.1016/j.tvj1.2011.05.019. 
Regan, T. (1983). The case for animal rights. Los Angeles: University of California press Berkeley.

Rollin, B. E. (2004). Annual meeting keynote address: Animal agriculture and emerging social ethics for animals. Journal of Animal Science, 82, 955-964.

Rollin, B. E. (2006). Euthanasia and quality of life. Journal of the American Veterinary Medical Association, 228, 1014-1016.

Rutgers, L. J. E., Swabe, J. M., \& Noordhuizen-Stassen, E. N. (2003). Het doden van gehouden dieren, Ja, mits... of nee, tenzij? Report Netherlands Organisation for Scientific Research (NWO)/Utrecht University.

Sapontzis, S. F. (1987). Morals, reason, and animals. Philadelphia: Temple University Press.

Singer, P. (1993). Practical ethics (2nd Edn). New York: Cambridge University Press.

Somers, J. G. C. J. (2004). Claw disorders and disturbed locomotion in dairy cows: The effect of floor systems and implications for animal welfare. PhD-thesis, Utrecht University, Utrecht.

Somers, J. G. C. J., Frankena, K., Noordhuizen-Stassen, E. N., \& Metz, J. H. M. (2003). Prevalence of claw disorders in Dutch dairy cows exposed to several floor systems. Journal of Dairy Science, 86, 2082-2093.

Spruijt, B. M., Van den Bos, R., \& Pijlman, F. T. A. (2001). A concept of welfare based on reward evaluating mechanisms in the brain: Anticipatory behaviour as an indicator for the state of reward systems. Applied Animal Behaviour Science, 72, 145-171.

Taylor, P. W. (1986). Respect for nature. A theory of environmental ethics. The attitude of respect for nature (pp. 59-86). Princeton: Princeton University Press.

Warnick, L. D., Janssen, D., Guard, C. L., \& Grohn, Y. T. (2001). The effect of lameness on milk production in dairy cows. Journal of Dairy Science, 84, 1988-1997.

Webster, A. J. F. (1995). Animal welfare: A cool eye towards Eden. London: Blackwell Science Ltd.

Yeates, J. (2009). Death is a welfare issue. Journal of Agricultural and Environmental Ethics. doi: 10.1007/s10806-009-9199-9. 